\title{
PROBLEMATIKA PEMBELAJARAN DARING MATA KULIAH GEOMETRI TRANSFORMASI DI MASA PANDEMI COVID-19
}

\author{
Karsoni Berta Dinata \\ karsoni.bertadinata@gmail.com \\ Universitas Muhammadiyah Kotabumi
}

\begin{abstract}
This study aims to analitis the problems of transformation geometry learning at the semester of the 2019/2020 academic year which are carried out online, then attempt to determine solutions and follow-up online learning based on the results of the evaluation. This research is a descriptive qualitative research. The research technique used was a survey technique. The research was carried out on students in semester 4 of the 2019-2020 academic year study program of mathematics education, FKIP Muhammadiyah Kotabumi University in the Transformation Geometry subject with 30 respondents as the object of research. The instrument used was in the form of a questionnaire consisting of 9 questions. The conclusions of this study are 1) it is better if lecturers in online learning use an application that is agreed upon at the beginning of the lecture and is easily accessible to students, 2) it is better if you prepare learning media / materials in the form of digital learning videos that can be accessed via YouTube, WhatsApp, or Instagram. etc., 3) uploading the syllabus, RPS, and material in the learning application, 4) providing lecture information must still be through the learning application and also shared via the WhatsApp Group, 5) providing a grace period for submitting assignments, 6) Continuing to carry out formative and diagnostic assessments for get feedback and return the results of UTS and UAS to Students.
\end{abstract}

Keywords: E-learning, digital learning media, Transformation Geometry

\begin{abstract}
Abstrak: Penelitian ini bertujuan untuk mengurai apa saja problematika dalam pembelajaran geometri transformasi semester genap tahun akademik 2019/2020 yang dilaksanakan secara daring, kemudian berupaya untuk menentukan solusi dan tindak lanjut pembelajaran daring kedepanya berdasarkan hasil evaluasi. Penelitian ini adalah penelitian kualitatif deskriptif. Teknik penelitian yang digunakan adalah teknik survey. Penelitian dilaksanakan pada mahasiswa semester 4 tahun tahun akademik 2019-2020 Prodi Pendidikan Matematika FKIP Universitas Muhammadiyah Kotabumi pada mata kuliah Geometri Transformasi dengan objek penelitian sebanyak 30 responden. Instrumen yang digunakan berbentuk angket yang terdiri dari 9 butir pertanyaan. Kesimpulan dari penelitian ini yaitu 1) sebaiknya dosen dalam pembelajaran daring menggunakan aplikasi yang disepakati di awal perkuliahan dan mudah diakses oleh mahasiswa, 2) sebaiknya menyiapkan media/materi pembelajaran dalam bentuk video pembelajaran secara digital yang bisa di akses melalui youtube, whatapps, atau instagram dll, 3) mengupload Silabus, RPS, dan materi di aplikasi pemeblajaran, 4) pemberian informasi perkuliahan tetap harus melalui aplikasi pembelajaran dan di bagikan juga melalui whatsap Group, 5) memberikan masa tenggang pengumpulan tugas, 6) tetap melakukan penilaian formatif dan diagnostik untuk mendapatkan umpan balik dan Mengembalikan hasil UTS dan UAS kepada Mahasiswa.
\end{abstract}

Kata Kunci: Pembelajaran daring, media pembelajaran digital, Geometri Transformasi 


\section{PENDAHULUAN}

Pandemi Covid-19 telah merubah tatanan hidup global, termasuk di indonesia. Sejak merebaknya Pandemi Covid-19 di Indonesia, pemerintah Republik Indonesia telah mengambil beberapa kebijakan dalam rangka mencegah penyebaran Covid-19. Salah satu langkah kebijakan yang diambil yaitu Fisycal Distancing dalam bentuk kebijakan pembatasan sosial berskala besar (PSBB). Kebijakan ini mengakibatkan perubahan tatanan sosial dimasyarakat dalam berbagai bidang termasuk di bidang pendidikan tinggi. Salah satu dampak Pandemi Covid-19 dalam bidang pendidikan tinggi yaitu mewajibkan mahasiswa belajar dari rumah (study from home). Hal ini berdampak juga pada Pembelajaran geometri transformasi yang diajarkan di semester genap tahun akademik 2019/2020 yang harus dilaksanakan dengan pembelajaran secara daring (e-learning).

Sebelum pandemi Covid-19, pembelajaran geometri transformasi diajarkan secara konvensional melalui tatap muka yang berlangsung di kelas. Perubahan dari model pembelajaran konvensional melalui tatap muka yang berlangsung di kelas menjadi model pembelajaran daring mewajibkan dosen dan mahasiswa harus siap menghadapi tantangan ini. Pada prinsipnya, baik pembelajaran tatap muka langsung atau daring bertujuan untuk mengembangkan kemampuan pemahaman konsep geometri transformasi. Menurut Dinata (2019) untuk mengembangkan pemahaman konsep geometri transformasi perlu ada upaya perbaikan pada proses pembelajaran yang dilakukan secara terusmenerus (kontinu).

Menurut (Trianto, 2012) Model pembelajaran adalah "kerangka konseptual sebagai prosedur sistematis dalam mengorganisasikan pengalaman belajar untuk mencapai tujuan belajar tertentu dan berfungsi sebagai pedoman bagi perancang pembelajaran dan para pendidik dalam merancang dan melaksanakan pembelajaran.

Hamzah \& Muhlisrarini (2014:154) menjelaskan model pembelajaran adalah "kerangka kerja konseptual tentang pembelajaran matematika yang digunakan dalam proses pembelajaran di dalam kelas agar suasana menjadi lebih menarik dan tujuan dari pembelajaran dapat dicapai oleh peserta didik".

Dengan demikian model pembelajaran merupakan kerangka konseptual berupa prosedur yang tersusun secara sistematis dalam mengorganisasikan pengalaman belajar yang akan digunakan dalam proses pembelajaran di kelas agar suasana pembelajaran menjadi menarik dan tujuan pembelajaran dapat dicapai oleh peserta didik.

Pembelajaran daring bisa diartikan sebagai proses pembelajaran yang memanfaatkan jaringan internet. Pembelajaran daring memungkinkan terlaksananya proses pembelajaran melalui fasilitas jaringan internet dengan menggunakan berbagai aplikasi tanpa harus bertatap muka langsung. Jadi model pembelajaran daring adalah kerangka konseptual berupa prosedur yang tersusun secara sistematis dalam mengorganisasikan pengalaman belajar yang akan digunakan dalam proses pembelajaran yang memanfaatkan jaringan internet sehingga suasana pembelajaran menjadi menarik dan tujuan pembelajaran dapat dicapai oleh peserta didik

Pandemi covid-19 membuat dosen dan mahasiswa menjadi lebih dekat (familiar) dengan berbagai aplikasi pembelajaran seperti zoom, google classroom, video converence, eddlink, whatsapps Group, dll. Menurut Jamaludin dkk (2020) menyatakan bahwa "Dalam kondisi adanya wabah Covid-19, pembelajaran daring dapat digunakan dengan pertimbangan memperhatikan kondisi mahasiswa dan dosen, sehingga akan terbiasa menyesuaikan dengan sistem daring, pembelajaran dapat terlaksana dengan baik". Ini merupakan sebuah tantangan bagi dosen dan mahasiswa untuk menjawab bagaimana 
pembelajaran daring dengan berbagai aplikasi tersebut menjadi pembelajaran yang efektif dan efisien. menurut Wahyono dkk (2020) menyatakan bahwa "pelaksanaan pembelajaran daring memiliki tantangan/kendala, baik dari aspek sumber daya manusia, saranaprasarana, dan teknis implementasi. Sebagai rekomendasi ke depan, dibutuhkan kemitraan publik dan keterlibatan banyak pihak secaraberkelanjutan. Kompetensi dan keterampilan guru/dosen harus terus diperkaya".

Perlu diketahui pembelajaran geometri transformasi semester genap tahun akademik 2019/2020 yang dilaksanakan secara tatap muka langsung di kelas hanya berlangsung 1 pertemuan saja. Selanjutnya mentaati aturan dari pemerintah agar pembelajaran tidak dilaksanakan tatap muka langsung dikelas maka sejak pertemuan ke-2 sampai pertemuan ke 16 pembelajaran dilaksanakan secara daring. Tentu saja perubahan ini sangat mengejutkan dosen dan mahasiswa. Dosen yg telah merancang pembelajaran dalam (RPS) tidak merancang RPS dengan menggunakan pembelajaran daring. Hal ini mengakibatkan terjadinya ketidakcocokan rencana pembelajaran dengan pembelajaran yang harus dilaksanakan.

Dosen dalam menyikapi hal ini, tentu saja harus menyesuaikan diri dengan kenyataan. Tuntutan pembelajaran daring secara penuh dalam satu semester mengharuskan dosen membuat persiapanpersiapan dan perencanaan-perencanaan dalam rangka pelaksanaan pembelajaran daring. Mengingat perubahan yang terjadi begitu cepat dan kurang diantisipasi oleh dosen, banyak sekali hambatan-hambatan yang dialami oleh dosen dan mahasiswa dalam proses pembelajaran daring. Permasalahan ini juga terjadi juga pada pembelajaran mata kuliah geometri transformasi.

Penelitian ini berupaya untuk melihat secara objektif apa saja problematika dalam pembelajaran geometri transformasi semester genap tahun akademik 2019/2020 yang dilaksanakan secara daring. Problematika pembelajaran akan diuraikan berdasarkan perspektif mahasiswa dan perspektif dosen. Data problematika pembelajaran geometri transformasi dari perspektif mahasiswa dikumpulkan melalui pemberian angket kepada mahasiswa. Selanjutnya data dari mahasiswa akan dikombinasikan dengan evaluasi internal dosen secara objektif.

Hasil dari evaluasi ini diharapkan dapat menjadi masukan untuk membangun pembelajaran daring kedepannya. Apalagi saat ini masa pandemi Covid-19 masih berlangsung, sehingga perlu adanya perbaikan pembelajaran daring sehingga proses pembelajaran menjadi lebih efektif dan efisien.

\section{METODE}

Penelitian ini adalah penelitian kualitatif deskriptif. Teknik penelitian yang digunakan adalah teknik Survey. Menurut Gunawan (2017) " teknik survey digunakan untuk mengumpulkan informasi dari sejumlah orang mengenai suatu topik atau isu tertentu". Penelitian dilaksanakan pada mahasiswa semester 4 tahun tahun akademik 2019-2020 prodi pendidikan matematika FKIP Universitas Muhammadiyah Kotabumi pada mata kuliah Geometri Transformasi dengan objek penelitian sebanyak 30 responden.

Adapun komponen yang diukur dalam angket atau kuesioner dituangkan dalam 9 pertanyaan yaitu; 1) Dosen menggunakan aplikasi perkuliahan online yang mudah di akses?, 2) Dosen memberikan tutorial dalam perkuliahan online?, 3) Informasi terkait perkuliahan disampaikan Melalui aplikasi?, 4) Dosen telah memberikan silabus, RPS dan Materi Secara online?, 5) Dosen memberikan kesempatan tenggang waktu untuk mahasiswa mengumpulkan tugas online?, 6) Dosen mengajar secara online sesuai jadwal perkuliahan?, 7) apakah dalam sistem daring ini mahasiswa optimal belajar dirumah? 8) Dosen melakukan evaluasi 
pembelajaran online secara objektif dan transparan?, 9) Biaya (kuota internet) yang digunakan untuk kuliah online relative mahal.

\section{HASIL DAN PEMBAHASAN}

Hasil penelitian berupa data hasil survey yang selanjutnya disajikan dalam diagram lingkaran (Proporsi) kemudian dianalisis secara deskrifip berdasarkan data dan evaluasi internal oleh dosen.

Analisis hasil penelitian diuraikan berdasarkan masing-masing pertanyaan pada angket. Selanjutnya diuraikan penjelasan terkait data yang disajikan, interpretasi hambatan/permasalahan berdasarkan evaluasi internal dosen, dan tindak lanjut/rekomendasi pembelajaran kedepan. Berikut penjelasannya.

1) Apakah dosen menggunakan aplikasi perkuliahan online yang mudah di akses?

Berdasarkan hasil suvey untuk pertanyaan "apakah dosen menggunakan aplikasi perkuliahan online yang mudah di akses?" diperoleh data sebagai berikut.

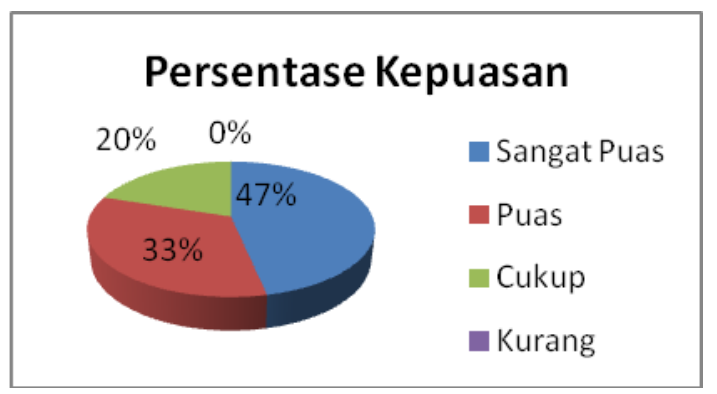

Gambar 1. Persentase kepuasan dalam kemudahan akses perkuliahan

Berdasarkan Gambar 1, sebanyak $47 \%$ mahasiswa sangat puas, $33 \%$ puas, $20 \%$ cukup dan $0 \%$ kurang puas terhadap kemudahan akses ke aplikasi pembelajaran yang digunakan oleh dosen. Hasil ini tentu saja cukup membanggakan, akan tetapi jika dicermati masih ada 20\% mahasiswa masih cukup puas.
Jika menengok kembali proses pembelajaran yang telah dilaksanakan berkaitan dengan aplikasi pembelajaran yang digunakan, selama ini aplikasi yang digunakan dalam pembelajaran daring matakuliah geometri transformasi yaitu Zoom, Whatsapps Group, Siakad, dan gmail. Penggunaan aplikasi zoom hanya dilaksanakan sebanyak 2 kali. Aplikasi Whatsapps Group digunakan sebagai media konsultatif. Aplikasi siakad untuk memberikan informasi perkuliahan sekaligus untuk mengisi jurnal perkuliahan. Gmail sering dipakai untuk pengumulan tugas mahasiswa.

Peneliti menduga penyebab masih ada mahasiswa sebanyak $20 \%$ yang masih cukup puas terhadap kemudahan akses pembelajaran berkaitan dengan penggunaan zoom dalam proses pembelajaran. Beberapa mahasiswa mengeluhkan kesulitan mengikuti pembelajaran yang dilaksanakan melalui zoom. Berbagai macam keluhan seperti belum menginstal aplikasi, sinyal, tidak punya kuota, atau mahasiswa yang sudah tergabung di pembelajaran tetapi penjelasan dari dosen sering terputus-putus dan beberapa peserta yg sering "keluar masuk" di zoom karena jaringan tidak stabil.

Solusi dan tindak lanjut dari permasalahan ini tentu saja tidak sepenuhnya ada ditangan peneliti. Tetapi ada beberapa strategi yang bisa dilakukan untuk memperkecil permasalahan tersebut yaitu: 1) di awal masa perkuliahan (pertemuan 1) dosen akan meminta untuk menginstal aplikasi zoom; 2) untuk menghindari jaringan tidak stabil, dosen akan melakukan pembelajaran menggunakan zoom dengan menggunakan jaringan wifi kampus yang lebih stabil dengan tetap menjaga sesuai protokol covid-19, 3) menyarankan mahasiswa menggunakan provider dengan jaringan yg lebih stabil di tempatnya masing-masing, 4) berkaitan dengan kuota internet, mahasiswa disarankan agar menggunakan bantuan kuota dari pemerintah dan kampus dengan sebaik-baiknya untuk proses pembelajaran. 
2) Dosen memberikan tutorial dalam perkuliahan online?

Berdasarkan hasil suvey untuk pertanyaan "Dosen memberikan tutorial dalam perkuliahan online?" diperoleh data sebagai berikut.

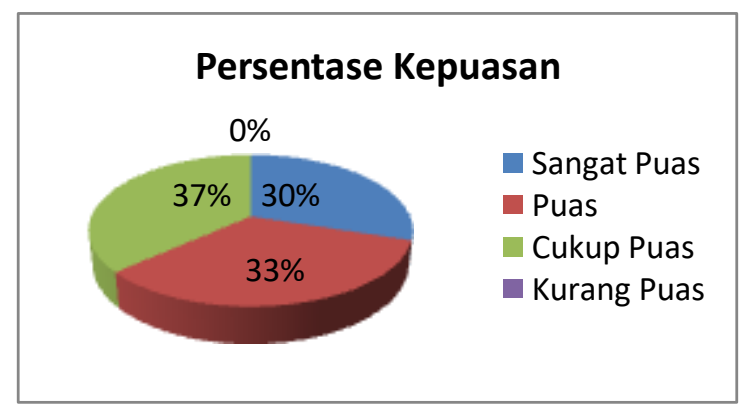

Gambar 2. Persentase kepuasan terhadap pemberian tutorial online.

Berdasarkan Gambar 2, dapat dilihat bahwa sebanyak 30\% mahasiswa sangat puas, sebanyak $33 \%$ mahasiswa menyatakan puas, tetapi masih ada sebanyak $37 \%$ mahasiswa cukup puas dengan tutorial yang dilaksanakan dosen dalam proses perkuliahan online.

Jika mencermati proses perkuliahan online yang telah dilakukan, hasil ini wajar mengingat pemberian tutorial langsung dengan menggunakan aplikasi zoom hanya beberapa kali saja.

Solusi dan tindak lanjut dari permasalahan ini adalah yaitu 1) pemberian tutorial dalam proses perkuliahan online dengan menggunakan zoom sebaiknya dilaksanakan sebanyak minimal 8 kali pertemuan; 2) sebaiknya menyiapkan media/materi pembelajaran dalam bentuk video pembelajaran secara digital yang bisa di akses melalui youtube, whatapps, atau instagram dll. Dinata \& Darwanto (2020) menyatakan bahan ajar/media ajar/materi aja apapun bentuknya baik digital atau konvensional harus tetap berfokus untuk meingkatkan kemampuan penalaran dan disposisi matematis mahasiswa.
3) Informasi terkait perkuliahan disampaikan Melalui aplikasi?

Berdasarkan hasil suvey untuk pertanyaan "Informasi terkait perkuliahan disampaikan melalui aplikasi?" diperoleh data sebagai berikut.

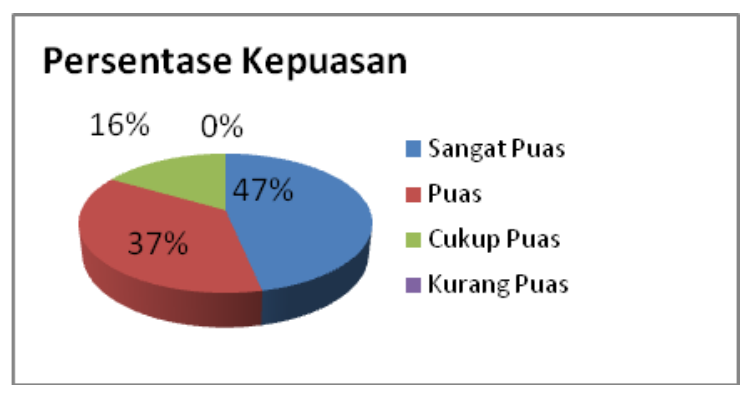

Gambar 3. Persentase kepuasan terhadap pemberian informasi melalui aplikasi.

Berdasarkan Gambar 3, tampak bahwa sebanyak $47 \%$ mahasiswa sangat puas, sebanyak $37 \%$ mahasiswa puas, dan sebanyak $16 \%$ mahasiswa menyatakan cukup puas dengan pemberian informasi perkuliahan melalui siakad.

Jika meninjau kembali proses pembelajaran yang telah dilakukan, pemberian informasi perkuliahan dilakukan dengan menggunakan siakad kampus. Selanjutnya informasi juga dilanjutkan di Whatsapp group. Sehingga informasi benar-benar sampai keseluruah mahasiswa.

Terkait dengan hal ini, tindak lanjut yang bisa dilakukan adalah kedepannya pemberian informasi perkuliahan akan dilakukan dengan cara sama seperti semester sebelumnya.

4) Dosen telah memberikan silabus, RPS dan Materi Secara online?

Berdasarkan hasil suvey untuk pertanyaan "Dosen telah memberikan silabus, RPS dan Materi Secara online?" diperoleh data sebagai berikut. 


\section{Persentase Kepuasan}

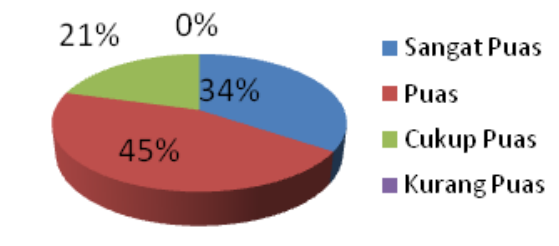

Gambar 4. Persentase kepuasan terhadap pemberian silabus, RPS dan materi.

Berdasarkan Gambar 4, tampak bahwa sebanyak 34\% mahasiswa sangat puas, sebanyak $45 \%$ mahasiswa puas, dan sebanyak $21 \%$ mahasiswa menyatakan cukup puas dengan ketersediaan silabus, RPS, dan materi.

Jika meninjau kembali proses pembelajaran mata kuliah geometri transformasi yang telah dilakukan, silabus dan RPS telah disampaikan pada saat pertemuan pertama. Materi pembelajaran diberikan setiap pembelajaran dimulai. Pemberian materi pembelajaran biasanya diberikan dalam bentuk power point, atau dosen memberikan link sumber pembelajaran yang bisa diakses mahasiswa atau memberikan perintah kepada mahasiswa untuk mempelajari materi dengan topik yang telah ditentukan kemudian mahasiswa bebas menentukan sumber belajar yang dipilih.

Tindak lanjut terkait dengan ketersediaan silabus, RPS dan materi perkuliahan yaitu 1) Mengupload silabus dan RPS di siakad pada matakuliah yang diampu, 2) menyiapkan materi perkuliahan dan diupload di siakad atau dishare di whatsapp group, 3) membahas materi yang diajarkan melalui zoom.

5) Dosen memberikan kesempatan tenggang waktu untuk mahasiswa mengumpulkan tugas online?

Berdasarkan hasil suvey untuk pertanyaan "Dosen memberikan kesempatan tenggang waktu untuk mahasiswa mengumpulkan tugas online?" diperoleh data sebagai berikut.

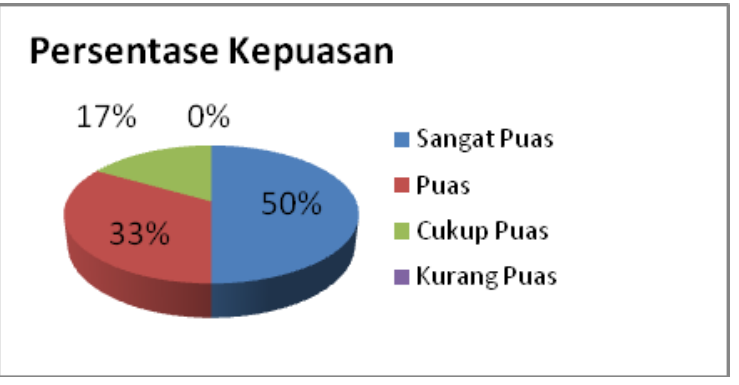

Gambar 5. Persentase kepuasan terhadap batas waktu tenggang pengumpulan tugas.

Berdasarkan Gambar 5, dapat dikatakan bahwa sebanyak 50\% mahasiswa sangat puas, sebanyak $33 \%$ mahasiswa puas, dan sebanyak $17 \%$ cukup puas dengan batas waktu tenggang pengumpulan tugas oleh dosen.

Berdasarkan evaluasi pembelajaran mata kuliah geometri transformasi yang telah dilakukan, batas waktu tenggang pengumpulan tugas oleh mahasiswa biasanya diberikan waktu selama 12 jam. Misalkan mata kuliah geometri transformasi berakhir pukul 11.59 maka batas akhir pengumpulan tugas berakhir pukul 23.59. Cara ini ditempuh dengan mempertimbangkan kendala-kendala yang dialami mahasiswa dalam mengumpulkan tugas misal.

Tindak lanjut yang akan diambil untuk pembelajaran selanjutnya berkaitan dengan batas waktu tenggang pengumpulan tugas yaitu tetap memberikan waktu tenggang kepada mahasiswa agar mengumpulkan tugas paling lambat 12 jam terhitung sejak berakhirnya pembelajaran.

6) Dosen mengajar secara online sesuai jadwal perkuliahan?

Berdasarkan hasil suvey untuk pertanyaan "Dosen mengajar secara online sesuai jadwal perkuliahan?" diperoleh data sebagai berikut. 


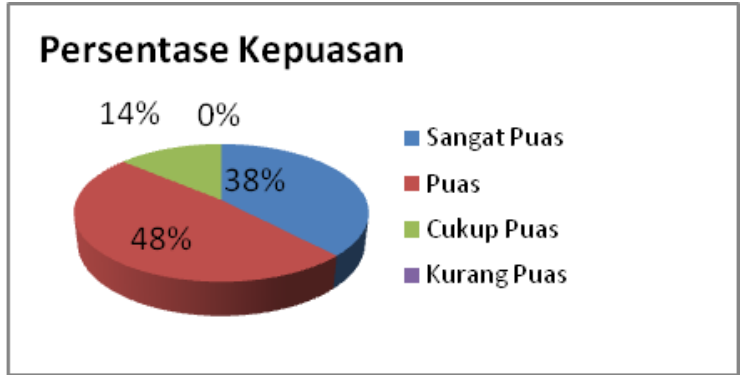

Gambar 6. Persentase kepuasan terhadap ketepatan mengajar.

Berdasarkan Gambar 6, tampak bahwa sebanyak 38\% mahasiswa sangat puas, sebanyak $48 \%$ mahasiswa puas, dan sebanyak $14 \%$ mahasiswa menyatakan cukup puas terhadap ketepatan mengajar dosen.

Berdasarkan evaluasi pembelajaran mata kuliah geometri transformasi yang telah dilakukan, pembelajaran mata kuliah geometri transformasi diupayakan dilaksanakan sesuai dengan jadwal mengajar yang telah ditetapkan. Memang harus diakui beberapa kali terjadi keterlambatan dalam memulai pem-belajaran, hal ini biasanya terjadi karena lupa atau karena sedang tidak berada dirumah dan tidak bawa laptop sehingga pembelajaran bisa dimulai setelah berada dirumah. Mengingat perubahan cara mengajar dari tatap muka langsung ke pembelajaran daring.

Solusi dan tindak lanjut dari permaslahan ini yaitu 1) mendownload aplikasi siakad cloud di android sehingga pembelajaran dapat dimulai tepat waktu, 2) meminta kepada mahasiswa mengingatkan dosen ketika sudah lewat 10 menit tetapi pembelajaran belum dimulai.

7) Apakah dalam sistem daring ini mahasiswa optimal belajar dirumah?

Berdasarkan hasil suvey untuk pertanyaan "apakah dalam sistem daring ini mahasiswa optimal belajar dirumah?" diperoleh data sebagai berikut.

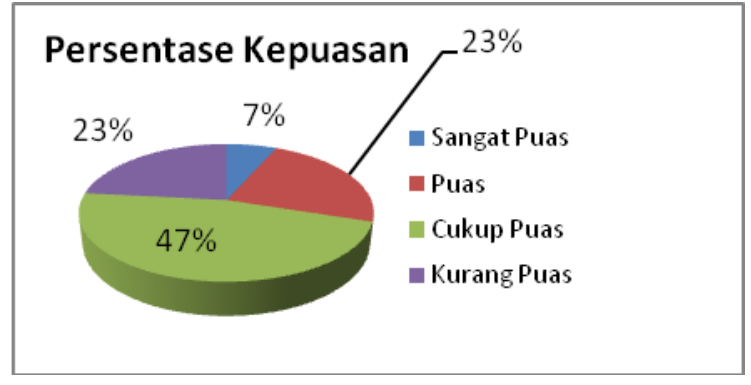

Gambar 7. Persentase kepuasan terhadap optimalitas belajar di rumah.

Berdasarkan dapat dikatan bahwa sebanyak $7 \%$ mahasiswa sangat puas, sebanyak $23 \%$ mahasiswa puas, sebanyak $47 \%$ cukup puas, dan sebanyak $23 \%$ mahasiswa tidak puas terhadap optimalitas belajar di rumah.

Hasil survey untuk indikator ini mungkin wajar, mengingat mahasiswa yang biasanya belajar langsung melalui tatap muka dikelas dan harus terbiasa dengan pembelajaran online.

Solusi dan tindak lanjut berkaitan dengan keoptimalan belajar mahasiswa di rumah, adalah dengan meningkatkan kualitas pembelajaran daring. Membimbing mahasiswa melalui tutorial yang diberikan melalui pembelajaran online. Dan membuat konten pembelajaran dalam bentuk digital.

8) Dosen melakukan evaluasi pembelajaran online secara objektif dan transparan?;

Berdasarkan hasil suvey untuk pertanyaan "Dosen melakukan evaluasi pembelajaran online secara objektif dan transparan?" diperoleh data sebagai berikut.

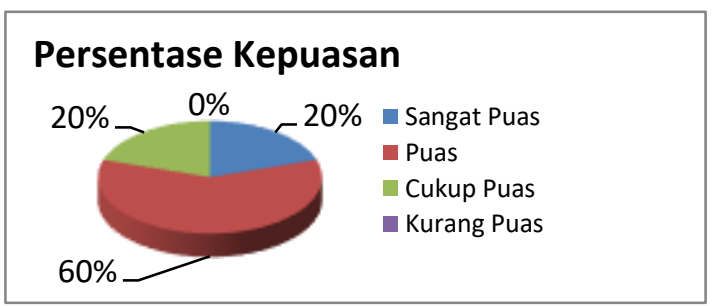

Gambar 8. Persentase kepuasan terhadap evaluasi pembelajaran. 
Berdasarkan Gambar 8, tampak bahwa sebanyak 20\% mahasiswa sangat puas, sebanyak $60 \%$ puas, dan sebanyak $20 \%$ cukup puas terhadap evaluasi yang dilakukan oleh dosen selama pembelajaran daring.

Berdasarkan evaluasi internal proses pembelajaran matakuliah geometri transformasi berkaitan dengan evaluasi/ penilaian mahasiswa, penilaian hanya bersifat sumatif. Penilaian bersifat formatif dan diagnostik jarang dilaksanakan selama proses pembelajaran mengingat proses perkuliahan yang jarang menggunkan zoom.

Solusi dan tindak lanjut dari permasalahan ini adalah dengan cara yaitu 1) melaksanakan perkuliahan secara daring dengan menggunakan zoom, dan memanfaatkan waktu tatap muka untuk berdiskusi, 2) memberikan kembali hasil UTS atau UAS, 3) menggunakan metode pembelajaran Asessment for Learning (AfL)

9) Biaya (kuota internet) yang digunakan untuk kuliah online relative mahal;

Berdasarkan hasil suvey untuk pertanyaan "Biaya (kuota internet) yang digunakan untuk kuliah online relative mahal?" diperoleh data sebagai berikut.

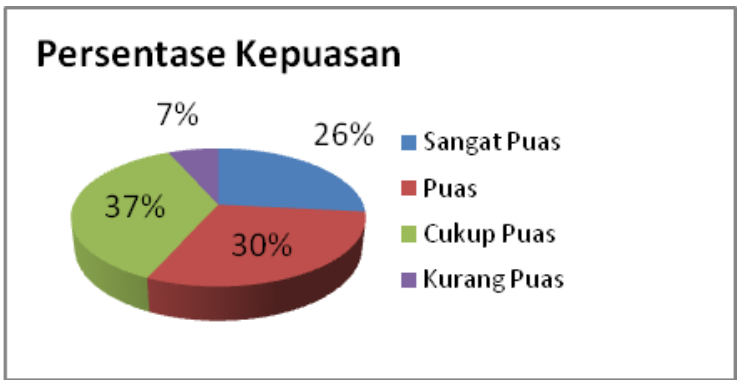

Gambar 9. Persentase kepuasan biaya pembelajaran online.
Berdasarkan Gambar 9, tampak bahwa sebanyak 26\% mahasiswa sangat puas, sebanyak 30\% mahasiswa puas, sebanyak $37 \%$ mahasiswa cukup puas, dan sebanyak 7 persen mahasiswa kurang puas. Dari data ini dapat disimpulkan bahwa mayoritas mahasiswa menyatakan bahwa pembelajaran daring relative mahal.

Saat ini pemerintah telah membuat kebijakan untuk memberikan bantuan kuota kepada mahasiswa untuk proses pembelajaran daring. Tentu saja kebijkan ini sangat membantu mahasiswa yang memang mengeluhkan mahalnya biaya (kuota) internet untuk mengikuti pembelajaran daring.

\section{SIMPULAN}

Berdasarkan hasil penelitian dan pembahasan terkait hasil penelitian, maka agar pembelajaran daring kedepanya lebih efektif dan efisien, berikut diperoleh simpulan yang bisa dilakukan oleh dosen yaitu 1) sebaiknya dosen dalam pembelajaran daring menggunakan aplikasi yang disepakati di awal perkuliahan dan mudah diakses oleh mahasiswa, 2) sebaiknya menyiapkan media/materi pembelajaran dalam bentuk video pembelajaran secara digital yang bisa di akses melalui youtube, whatapps, atau instagram dll, 3) mengupload Silabus, RPS, dan materi di aplikasi pemeblajaran, 4) pemberian informasi perkuliahan tetap harus melalui aplikasi pembelajaran dan di bagikan juga melalui whatsap Group, 5) memberikan masa tenggang pengumpulan tugas, 6) Tetap melakukan penilaian formatif dan diagnostik untuk mendapatkan umpan balik dan Mengembalikan hasil UTS dan UAS kepada Mahasiswa. 


\section{DAFTAR RUJUKAN}

\section{Buku:}

Gunawan, H., (2017). Dasar-Dasar Metodologi Penelitian Pendidikan. Fakultas Tarbiyah dan Keguruan UIN Sunan Gunung Djati, Bandung.

Hamzah, Ali dan Muhlisrarini. 2014a. Perencanaan dan Strategi Pembelajaran Matematika. Jakarta: Rajagrafindo Persada.

Trianto. 2012. Model Pembelajaran Terpadu. Jakarta: Bumi Aksara.

\section{Artikel dalam jurnal online:}

Dinata, K. B. (2019). Problematika Membangun Pemahaman Konsep Geometri Transformasi Mahasiswa Pendidikan Matematika di Universitas Muhammadiyah Kotabumi Tahun Akademik 2019/2020. Eksponen, 9(2), 01-09.

Dinata, K. B., \& Darwanto, D. (2020). Pengembangan Bahan Ajar Peluang Dengan Pendekatan Kontekstual Berorientasi Pada Kemampuan Penalaran Dan Disposisi Matematis Berbasis Android. Eksponen, 10(1), 1-10.

Wahyono, P., Husamah, H., \& Budi, A. S. (2020). Guru profesional di masa pandemi COVID-19: Review implementasi, tantangan, dan solusi pembelajaran daring. Jurnal Pendidikan Profesi Guru, 1(1), 51-65.

Jamaluddin, D., Ratnasih, T., Gunawan, H., \& Paujiah, E. (2020). Pembelajaran daring masa pandemik Covid-19 pada calon guru: hambatan, solusi dan proyeksi. LP2M. 